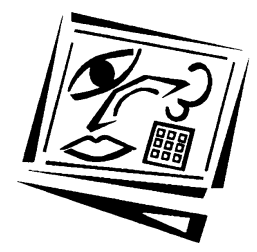

\title{
Relativity in a rock field: A study of physics learning with a computer game
}

\author{
David Carr and Terry Bossomaier \\ Charles Sturt University
}

\begin{abstract}
The Theory of Special Relativity is widely regarded as a difficult topic for learners in physics to grasp, as it reformulates fundamental conceptions of space, time and motion, and predominantly deals with situations outside of everyday experience. In this paper, we describe embedding the physics of relativity into a computer game, and present the results of a study on its effectiveness for learning. The game, which is based on Asteroids, enables learners to interact with the physics, and observe and contrast their effect with Newtonian mechanics. The principal relativistic effects of length contraction, mass dilation and time dilation are each portrayed, and key with the learning outcomes of the Australian Higher School Certificate (HSC) high school physics course. Key findings from the study conducted with both students studying HSC physics, and participants without physics training, show that the game on its own serves as a powerful introduction for building up accurate qualitative descriptions of relativistic physics effects; in addition, learners generally reported finding the game accessible and interesting. However, establishing deeper understanding of the physics requires further reflection on the part of the learners than the game itself tends to facilitate. We conclude by discussing implications for design and integration of game-based learning with traditional teaching in relation to the topic of special relativity.
\end{abstract}

\section{Introduction}

The Theory of Relativity (Einstein, 1924) is one of the most important results of modern physics. It represents the basis of much of our understanding about the universe, and is also a part of many fields of science and everyday technologies, including computers and the global positioning system. With relativity, Einstein presented a new model that elegantly reconciled a deep contradiction that had arisen between the classical laws of physics described by Newton, and experimental results by Michelson and Morley, with the insight that the speed of light remained constant regardless of the velocity of the observer. His reformulation meant that space and time, which were traditionally thought of as being constant, were instead shown to be changeable; and likewise, the speed that light is observed to travel at would always be constant, irrespective of the relative velocity of the light source.

These results appear to run counter to people's intuitive understanding, and lead to such unexpected effects as length contraction, time dilation and mass dilation (some background is provided in the following Literature review section). Relativity is a challenging topic for new learners (Scherr, Shaffer \& Vokos, 2001; 2002; Dimitriadi, Halkia \& Skordoulis, 2005), as it deals with phenomena outside of everyday experience and which cannot easily be directly observed in real life. Thus, learners usually have to 
rely on abstractions and thought experiments to grasp the basic ideas of relativity and its consequences.

Interactive computer-generated environments can be programmed to behave according to Newtonian principles of physics, or other rules (Squire, Barnett, Grant \& Higginbotham, 2004; Price, 2008). Computers thus offer a way of providing some experience of relativity (Hsiung \& Dunn, 1989; Weiskopf et al, 2005), much as envisaged by George Gamow in his Mr Tompkins series (1940). In this paper we describe developed software that places relativity into the context of a computer game. The game takes the form of a re-imagining of the classic action arcade game Asteroids (Wikipedia, 2010), with special relativistic physics in place of Newtonian featuring prominently. This is an application of computer games for teaching and learning - the domain of "serious games" (de Freitas, 2006; Dondlinger, 2007; Gee, 2003; Gros, 2007; Mayo, 2007, 2009).

A research project was undertaken to evaluate the design of the game and quantify its effectiveness for fostering understanding of relativity, as part of our research into simulation and game-based learning of physics. Experimental studies were conducted with high school students currently enrolled in studying physics, and with volunteers with no formal background or training in physics. In the findings presented in this paper, these participants are collectively characterised into a prior knowledge cohort (i.e. have previously studied relativity), and a new learner cohort. The experiments aimed to measure the learning effect from playing the game through pre- and post-tests, focusing on key relativistic concepts (space contraction, time dilation and mass dilation); and also to collect participants' evaluations and attitudinal responses to the game. The primary research question is:

RQ I: Can computer game software embodying relativistic principles provide an effective scaffold for learning of the Theory of Relativity?

In addition, we address the following auxiliary questions:

RQ II: How does learning with the game compare to or supplement the knowledge gained from formal classroom tuition?

RQ III: What design and implementation factors can be identified that would make such educational relativity games appeal to, motivate and engage a diverse audience without compromising learning?

\section{Literature review}

For the uninitiated, a brief introduction to relativity is given below for context, followed by a review of background in the domain of learning with games and computers.

\section{Special Theory of Relativity}

Einstein's Theory of Relativity (1924) has two parts; this paper focuses only upon the part of the theory known as Special Relativity. A descriptive overview is given here; the interested reader may refer to Appendix A for the (condensed) mathematical derivations. 
Under the classical model of physics, it was thought that light would behave similarly to sound, which propagates as waves through some medium (such as air). Given a sound source that is stationary relative to the medium (i.e. with respect to a 'frame of reference'), an observer in a state of relative motion (e.g. approaching the source) will measure a change in the speed of propagation of the wavefront, as predicted by the theorem of the addition of velocities. Classical mechanics likewise assumed that the speed of light must change based on the relative velocities of the light source and observer. However, experiments in the late 1800s (such as that performed by Michelson and Morley) involving the speed of light, found it was always the same. In attempting to reconcile this outcome with Newtonian physics, the straightforward solution seemed to be that a modification to the physical laws was required for observers in motion. However, such solutions implied the existence of a 'universal' frame of reference for measuring all motion against - an unsatisfactory outcome that opens a theoretical 'can of worms'.

Einstein's solution was a complete reformulation of physics. To develop his theory, Einstein used the following two postulates:

1. The laws of physics are the same to all inertial observers. This frames the principle that there should be no privileged 'universal' frame of reference for describing physics.

2. The speed of light is the same to all inertial observers. This asserts that the speed of light, $c$, will always be the same (or invariant) to all observers in all frames of reference, irrespective of relative velocities. To accommodate this, Einstein had to throw out previous notions (from classical mechanics) about space and time being invariant, replacing them with the insight that they are in fact changeable.

Although these concepts may appear to be counterintuitive, Einstein's model actually succeeds in providing a simplified and unified description of the physical phenomena, and his results were later borne out by experiment.

Two principal effects that arise from Einstein's model are space contraction and time dilation. Since speed (or velocity) is a measure of distance travelled over time, as a consequence of invariant light speed, special relativity reveals that the dimensions of space and time must change for an observer in a state of inertial motion relative to one who is stationary. Thus, space contracts along the direction of travel, and time slows down.

In addition, as an indirect result of the famous equation $E=m c^{2}$ relating energy and mass, it is sometimes said (see Gibbs, Carr \& Koks, 2008) that mass increases with increasing speed, due to kinetic energy; an effect referred to as mass dilation.

Since the effects of relativity only become apparent at very high speeds (approaching the speed of light), they are not normally directly observable by humans. Efforts to explain and popularise relativity for wider general audiences in accessible and entertaining ways include the seminal story Mr Tompkins in Wonderland (Gamow, 1940). In the story, the title character Mr Tompkins explores a dream world where the speed of light is only about $30 \mathrm{~km}$ per hour, and relativistic effects enter into everyday activities such as riding a bicycle, where the bicycle and rider are 'squashed' (Figure 1). 


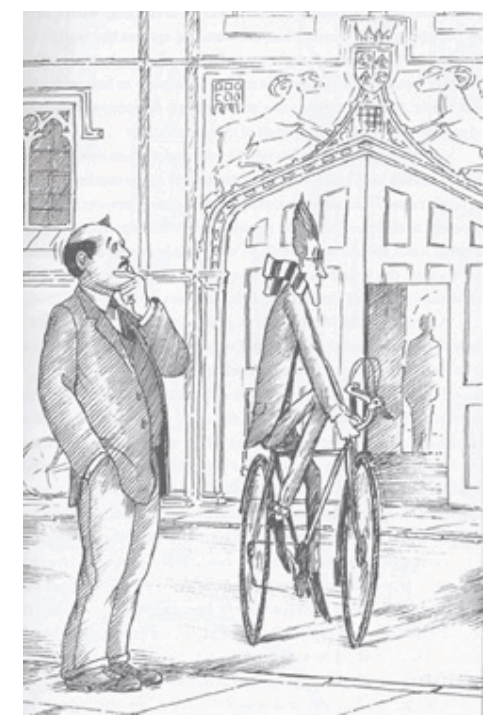

Figure 1: Example illustration from Mr Tompkins in Wonderland (Gamow, 1940)

\section{Serious games}

The last decade has seen a steady decline in enrolments in computer science in many parts of the developed world (Andriole \& Roberts, 2008; Rashid, 2008). Similarly the other so-called STEM disciplines (science, technology, engineering and mathematics) have also declined in attractiveness as career choices, and are still male dominated (Price, 2006; Mayo, 2007). Many factors and possible solutions have been discussed, but a strong common element is the need for a more engaging experience in high school. Given the enormous popularity of computers amongst today's youth, from social networks to computer games, better, more computer aware teaching tools would seem to be a positive step.

The serious or epistemic games movement advocates computer games as effectively solving jointly the problems of motivation (Prensky, 2001) and advanced skill development (Gee, 2003), as well as informing effective pedagogical design and approaches (Schiller, 2008). Extensive reviews of the literature and case studies on learning with games can be found in publications by de Freitas (2006) and Dondlinger (2007), and is also discussed by Egenfeldt-Nielsen (2007) and Gros (2007) in the context of evolving pedagogic design. Egenfeldt-Nielsen (2007) characterises educational games into three generations: behaviourism-based "Edutainment" (involving simple skill-and-drill and rote learning tasks), cognitivist-constructivist approach (learnerfocused, using multimedia to present and scaffold information), and situated-learning constructionism (using games as a platform for social and exploratory learning). The first generation has a narrow view of learning, while the later generations encapsulate more compelling and inclusive methods. Amory (2007), Kiili (2007) and Schiller (2008) present frameworks for quantifying the pedagogical content of games, both for informing the design of educational games and reflecting on good teaching practices. Gorriz and Medina (2000) also argue that games can help to interest more girls in computer science, while Mayo (2009) collates evidence from several studies in STEM games giving improvements in learning outcomes between 7 and $40 \%$. 
But there are counter arguments. Gros (2007) cautions that games are not the solution to educational problems - engagement and motivation are interesting benefits, but are not enough by themselves. In a study correlating leisure gaming activity with academic performance, Ip, Jacobs and Watkins (2008) found that frequent gamers generally achieved lower marks than less frequent gamers, suggesting at least that the benefits of exposure to leisure games did not outweigh reduced time on task. Kaminski, Sloutsky and Heckler (2008) discovered the somewhat surprising result that undergraduate students generalise better in maths if they are taught the generic principles first, rather than see the abstractions motivated by concrete examples. This suggests that it is worth asking if games should be the first contact with a domain (concrete representation type games as described here) or whether they should follow exposure to formal generic descriptions of the domain. Shayer, Ginsburg and Coe (2007) find that there has been a decline in the last decade of students' abilities to make physical judgments, say relating to weight or volumes of liquids. They attribute this to computer games - an increasing interaction with worlds only through the media of vision and sound, perhaps. This opens up the issue as to whether experience in a virtual world will transfer across to the visceral properties of the real world.

\section{Teaching physics}

We now look at examples of games and their applications specifically in teaching science and physics. In a recent publication, Stewart (2009) reported on a serious game Physics Geeks and experimental results utilising a small group of learners. The game consists of a series of concept-targeted 3D virtual world modules where students interact with the environment and then answer physics questions, and are able to compare scores with their friends. The results of the experiment showed that the experiment group had significantly greater score gains than a control group, although the sample size $(n=13)$ was small. Price $(2006 ; 2007 ; 2008)$ has presented a similar approach utilising the commercial computer game Unreal Tournament 2004 to present physics constructs interactively, using specially-constructed "immersive environments" to engage students in enquiry-based "active learning" (Price, 2007). Although learning outcomes were not measured, in attitudinal surveys students reported better learning experiences using the game alongside most concepts (Price, 2006; 2008).

While these first two examples are rooted in the realm of mechanics familiar in day to day life, real world embedding is absent from the seminal electromagnetism game Supercharged! (Squire et al, 2004). Designed for American middle-school students (about age 13), this game embodies a novel simulation environment to foster hands on learning and understanding through solving puzzles involving charged particles and magnetic fields. Supercharged! thus represents a unique strength of computer games, as the electrostatics principles around which the gameplay is built are quite different to the physics of traditional games. Zuiker, Anderson, Lee and Chee (2008) also described teaching the topic of electromagnetism using a multi-user game, Escape from Centauri 7, which was embedded in a curriculum of collaborative learning in a Singapore boys' high school with students aged 14-15. In investigations, both authors reported that students who played the game developed a more intuitive and descriptive understanding of physics phenomena, and that the game provided an effective focus for shared learning through group discussion, although the latter was largely dependent on the teacher as facilitator. 
We arrive now at the topic of relativity, which occupies a core component of the Australian Higher School Certificate (HSC) curriculum for physics in Years 11 and 12 in New South Wales high schools (Board of Studies, 2010), as well as tertiary education in physics. Although this topic has had many efforts directed towards realising computer simulations, there have been no prior efforts to embed it in serious games.

Following work on the appearance of moving objects taking into account relativistic effects (Boas, 1961; Terrell, 1959), much of the development of relativistic simulations has focused on visualisation of relativistic scenarios - representing how things would look to an observer, taking into account effects including Doppler shift and relativistic aberration of light (Weiskopf, Kraus \& Ruder, 1999; Savage \& Searle, 1999; Hsiung \& Dunn, 1989). Recent advances in hardware made possible the development of techniques for interactive, real-time computation of relativistic scenes, such as embodied in the virtual relativistic 'flight simulator' Real Time Relativity presented by Savage, Searle and McCalman (2007). This simulator enables students to explore relativistic effects and observe the rich visual phenomena that result from high speed motion. In laboratory classes that balance directed activities with open ended exploration, the authors report that students who use the software found relativity to be less abstract and improved on questions relating to conceptually challenging aspects of relativity (McGrath, Savage, Williamson, Wegener \& McIntyre, 2008; Savage, McGrath, McIntyre, Wegener \& Williamson, 2010; McGrath, Wegener, McIntyre, Savage \& Williamson, 2010).

Although this simulation is described as "game-like" (Savage, Searle \& McCalman, 2007), it nonetheless lacks the defining features of a game. We provide a definition of games as comprising of rules, and a goal (as distinct from simulations, which embody only rules). The challenge of achieving the goal, in competition with other entities or the system itself, is largely responsible for the sense of 'fun' and engagement for players. It is this unique quality of games that is seen to have potential benefits in motivating learners to spend more time on task; moreover, the game can be structured to frame enquiry, and provide 'scaffolding' to direct and support learning by the user (Schiller, 2008).

\section{Methodology}

We developed a prototype game, which embodies features of special relativity in its graphics and gameplay (Carr, Bossomaier \& Lodge, 2007; Carr, 2010). The physics principles embodied in the game match closely with the learning outcomes of the HSC physics syllabus (Board of Studies, 2010). The game is described in the following section.

Players engage directly with the rules of relativity in interacting with an open game environment, promoting learning by cognitive and constructivist principles (Egenfeldt-Nielsen, 2007). To evaluate the game, an experimental model was devised, and ethics in human research approval granted for trials with student participants. Participants were recruited voluntarily from three local high schools, and internally within Charles Sturt University (CSU). Table 1 summarises the participant audience that partook in the experimental study, characterised into prior knowledge and new learner cohorts. Questionnaires (both paper based and online forms) were used to collect user's impressions of the game and test their knowledge. In pursuance of our research questions, the main focus of the questionnaire was in finding out whether 
exposure to the game improves test scores. Our research procedure is outlined in subsequent sections.

Table 1: Summary of participants involved in the study

\begin{tabular}{|l|l|c|c|c|}
\hline \multicolumn{2}{|c|}{} & \multicolumn{3}{c|}{ Cohort } \\
\cline { 3 - 5 } \multicolumn{2}{|c|}{ Source } & Uni volunteers & HSC students & Prior knowledge \\
\hline \multicolumn{2}{|c|}{ Count } & 26 & 13 & 28 \\
\hline \multirow{2}{*}{ Gender } & Males & 17 & 5 & 20 \\
\cline { 2 - 5 } & Females & 9 & 8 & 8 \\
\hline \multirow{3}{*}{ Age } & Average & 25 & \multicolumn{3}{c|}{16.8} \\
\cline { 2 - 5 } & Oldest & 45 & \multicolumn{2}{c|}{18} \\
\cline { 2 - 5 } & Youngest & 17 & \multicolumn{2}{c|}{16} \\
\hline
\end{tabular}

\section{Game design}

Our game design, Relativistic Asteroids (RA), is a re-imagining of the classic video arcade game Asteroids with relativistic physics. The game is implemented in $\mathrm{C}++$ for Microsoft Windows operating systems and uses the Microsoft DirectX 9.0c API for graphics calls. Figures 2 and 3 show screenshots of the game in action.

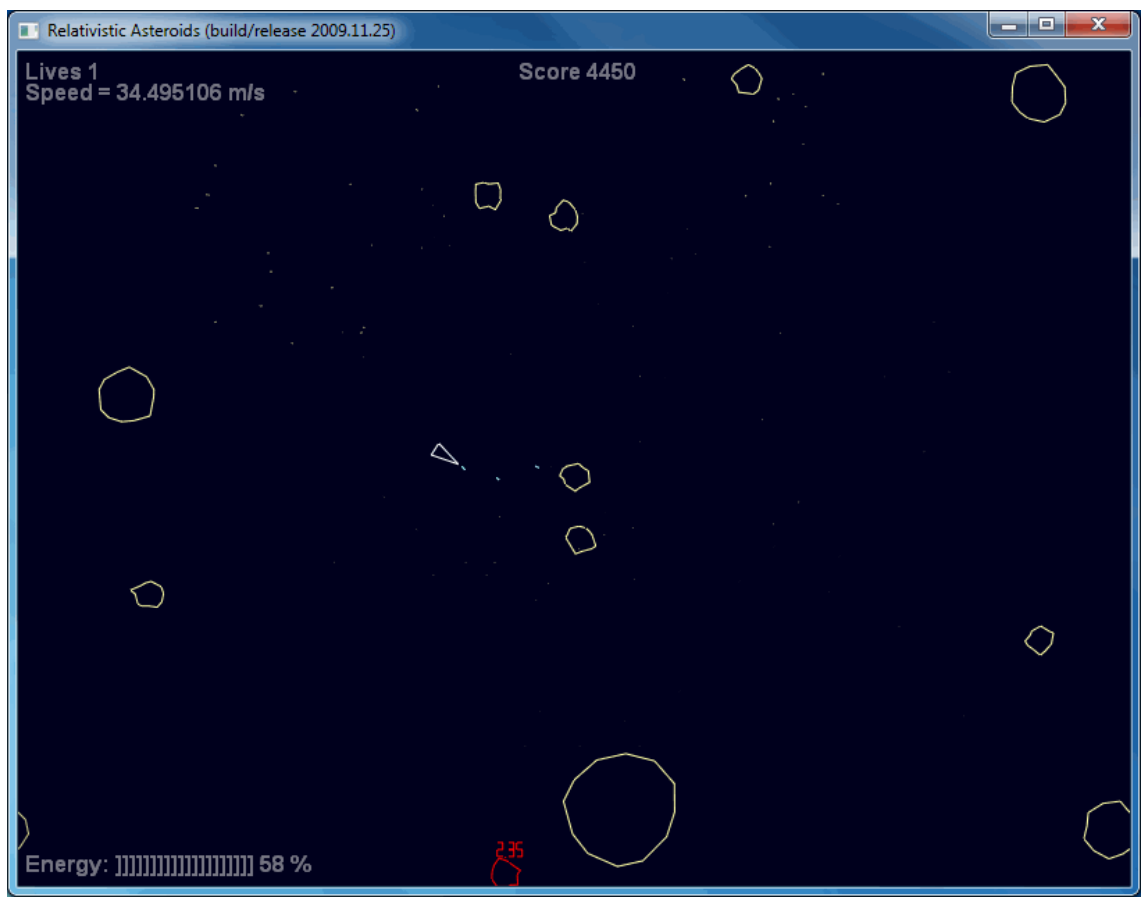

Figure 2: The Relativistic Asteroids game being played in classical mechanics mode

RA is a two-dimensional game played with third-person perspective. The player manoeuvres a spaceship (rendered as a white triangle) around the game screen, shooting drifting asteroids. The primary controls consist of forward thrust; left (counter-clockwise) and right (clockwise) rotation; and a fire button. The objective of the game is to shoot and destroy the asteroids, earning the player points, while 
avoiding collision with the fragments. When all the asteroids have been destroyed the player progresses to the next level and a new batch of asteroids is generated, and so on until the player quits or loses all their lives.

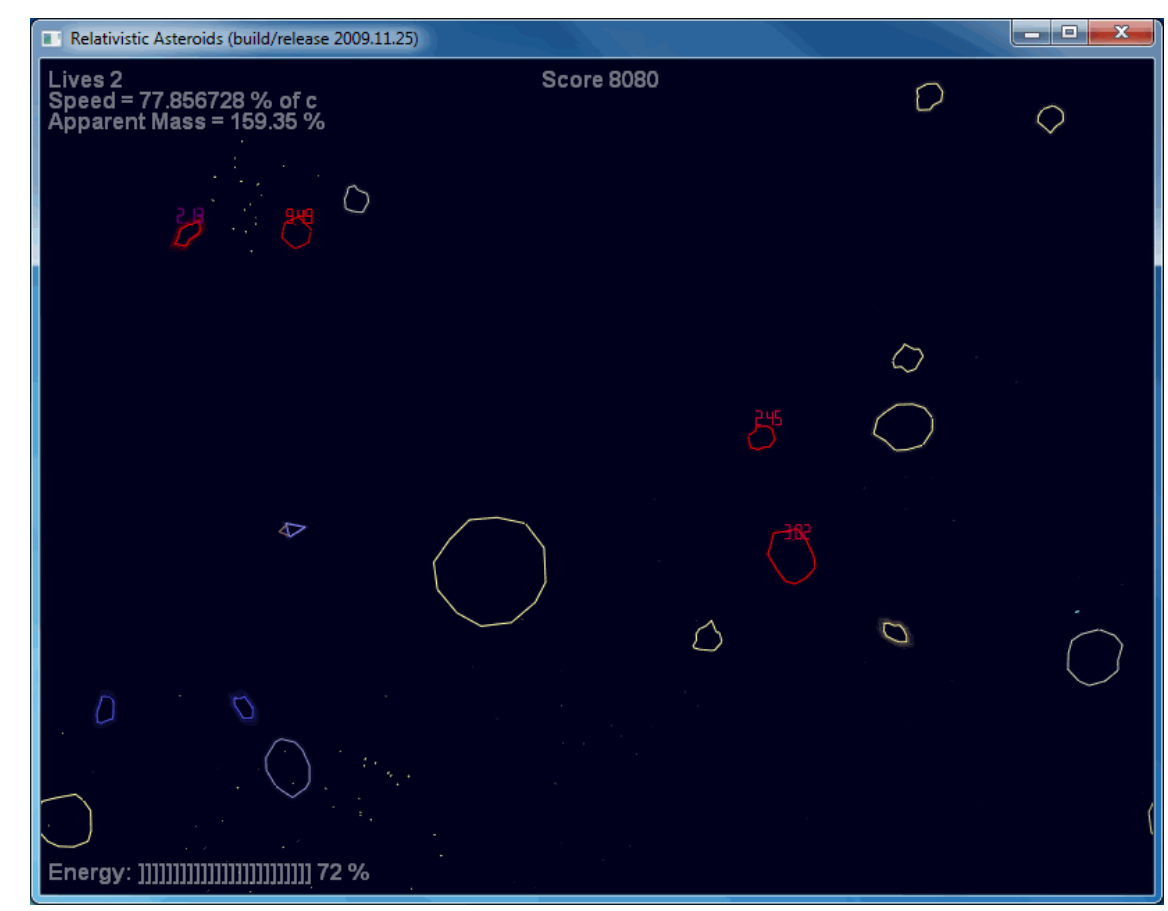

Figure 3: The game being played in relativistic mechanics mode, exhibiting relativistic effects

After Squire et al (2004), we embed the concepts we wish to communicate to learners in the game's mechanics, necessitating learning the concept to win. Asteroids was chosen as a game template to develop with relativistic physics due to the gameplay being based around the interactions of objects moving under constant inertial motion. The ship was thought to be an ideal way of communicating the concept of 'relativistic mass', as its inertia and handling will change with velocity as compared to the classical case (for exposition, see Gibbs, Carr \& Cox, 2008). The game provides an open environment for players to interact with the physics, eliciting their conceptions as they explore and experiment, and promoting comparison and reflection. This is learning by constructivist principles, and in terms of Egenfeldt-Nielsen's (2007) evolutionary outline, represents a 'second-generation' educational game design.

RA can be played in several different game modes, and utilises Gamow's (1940) device of varying the speed of light. The in-game light speed can range from infinity, corresponding to classical physics, down to a value that allows relativistic effects to readily enter into the gameplay. Objects travelling at speeds close to the in-game speed of light show increased relativistic effects:

- Length contraction is portrayed literally, much like the cyclist example in Figure 1. This is not totally realistic, but can be thought of as an approximation of the special 
case where pure Lorentz contraction is visible to an observer (Scott \& van Driel, 1970).

- Mass dilation affects the handling of the player's ship and the outcomes of elastic collisions between asteroids. It is also shown visually with objects being drawn with a proportionally thicker outline.

- Time dilation is shown in countdown timers on a special type of 'time bomb' asteroid, and in time-based behaviours of the spaceship (turning and fire rate).

- An approximation of the Doppler shift effect on light is included. Similar to the changing pitch of sound, this is the effect of the wavelength of visible light being shifted toward either the blue or red end of the spectrum due to relative velocity, producing a change of colour (see Savage \& Searle, 1999; Savage, Searle \& McCalman, 2007). The effect is calculated relative to the centre of the screen, so that objects moving from the edges toward the centre are treated as approaching (blueshift), and those moving to the edges are receding (redshift).

A dashboard shows information such as the player's score and the ship's current speed as a percentage of light speed. In addition to game modes where the player competes for points under various light speed conditions, a 'practise' mode provides additional scaffolding to facilitate freer experimentation by players without penalties like dying (Carr, 2010).

Figure 2 shows the game being played in the classical mechanics mode. The player's spaceship (white triangle) is shown shooting at some asteroids (yellow outlines); a red 'time bomb' asteroid with countdown timer is also visible at the bottom of the screen. Objects in motion display no special features. In Figure 3, the game is being played with the relativistic 'slow light' mechanic. The player's spaceship is shown travelling from the left toward the centre of the screen at about $78 \%$ of light speed (as reported in the dashboard text in the upper left), and exhibits length contraction and blueshift. Asteroids also portray contraction and colour shift (as in Figure 4), and time dilation in the timers of 'bomb' asteroids.
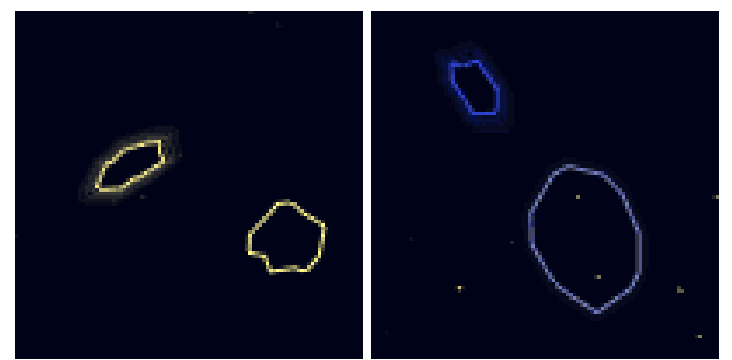

Figure 4: Asteroids portraying varying degrees of length contraction (left) and blueshift (right)

\section{Survey instrument}

The survey comprises three sections: a knowledge test, evaluation of the game, and demographics questions. Established survey models were referenced as examples in formulating and ordering the questions, including the Job Satisfaction Survey (JSS) 
designed by Spector (1985); Davis' (1989) Perceived Usefulness and Ease of Use survey; web survey methodologies (Ritter \& Sue, 2007); and a survey for the evaluation of instructional aids by Strachota, Schmidt and Conceição (2006).

1. The test section comprises 8 multiple choice examination questions on relativity, intended to obtain a quantitative measurement of each participant's knowledge. The first five questions were devised to approximate HSC-level (factual) questions; three directly relate to the three principal effects portrayed in the game. The following two questions were modelled after more difficult (problem-solving) examples, to examine whether respondents could extrapolate more complex ideas, and the final question was factual but based on more advanced topics from relativistic visualisation (see Literature review). Questions are summarised here in Table 2 and given in full in the appendix.

Although 8 questions are not very many, the number of questions was limited in all parts of the questionnaire owing to time considerations. This study used a pre-post paired design where subjects answered the 8 questions before playing the game, and then re-took the same 8 questions after, with each subject's pre-post answers being directly compared. Although this carries the potential for bias, since subjects know the questions the second time around, this limitation was judged acceptable in the interests of making direct comparisons.

2. After playing the game, participants completed an evaluation section comprising 10 statements about the game. The wordings of the statements were in part informed by the above survey templates, and are given in Table 3. Two statements relate to the perceived quality and entertainment value of the game $(V)$, and the remaining eight are about perceived effectiveness for learning, four in general terms $(G)$ and four dealing with targeted topics $(T)$. Statements were scored using a 5-point Likert scale, from 'Strongly agree' (+2) to 'Strongly disagree' (-2).

After Spector's JSS (1985), statements are written in both directions: eight of the statements describe positive reflections of the game, and the remaining two are negative. Respondents are also able to provide comments on the best features of the game and suggest how it could be improved. The aim of this section was to collect any interesting insights from users about the design and quality of the game experience.

3. A demographics section asks the respondent to supply general non-identifying information about themselves, including age, gender, and previous learning of relativity; their interest in computer games; and also allows them to provide any other comments.

Table 2: Summary of test section questions

\begin{tabular}{|c|l|}
\hline No. & \multicolumn{1}{|c|}{ Question synopsis } \\
\hline 1. & Identify statement pairs (postulates) that correctly describe the Special Theory of Relativity. \\
\hline 2. & Describing length of a relatively moving object. \\
\hline 3. & Describing mass of a relatively moving object. \\
\hline 4. & Describing rate of ticking of a relatively moving clock. \\
\hline 5. & Speed of light as seen by a relatively moving observer. \\
\hline 6. & Change in the age of an airline pilot due to relativity. \\
\hline 7. & Description of simultaneous events from different frames of reference. \\
\hline 8. & $\begin{array}{l}\text { Effects on light emitted from relatively moving source (relativistic optics). (2 correct answers } \\
\text { selected from } 6 \text { statements) }\end{array}$ \\
\hline
\end{tabular}


Table 3: Statements used for evaluating the game

\begin{tabular}{|c|l|}
\hline Code & \\
\hline V1 & The game was fun to play. \\
\hline V2 & $\begin{array}{l}\text { Putting relativity into a computer game makes it more entertaining and motivating to } \\
\text { learn. }\end{array}$ \\
\hline G1 & The physics presentation in the game helped me to think about relativity principles. \\
\hline G2 & It was too difficult to learn the rules of the game. (Reverse statement) \\
\hline G3 & $\begin{array}{l}\text { I didn't really learn anything about the topic of relativity from playing this game. } \\
\text { (Reverse statement) }\end{array}$ \\
\hline G4 & Playing a game such as this would be an effective way to learn about relativity. \\
\hline T1 & $\begin{array}{l}\text { The game clearly demonstrates some of the differences between classical and relativistic } \\
\text { models of physics. }\end{array}$ \\
\hline T2 & The game clearly portrays the concept of relativistic length contraction. \\
\hline T3 & The game clearly portrays the concept of relativistic mass dilation. \\
\hline T4 & The game clearly portrays the concept of relativistic time dilation. \\
\hline
\end{tabular}

\section{Procedure}

An initial pilot run of the study (utilising a longer form of the survey) was conducted for five months through 2008, in which the questionnaire was trialled as a web survey. Subsequently, minor changes were made and the main study was conducted toward the end of 2009. This collected data from Year 11 and 12 classes at three high schools ( $\mathrm{n}=41$ students), and from experiment sessions conducted at CSU using volunteers without any physics background $(\mathrm{n}=26)$. (See Table 1 earlier.) Only results from the main study are presented here.

On campus experiment sessions were conducted in CSU's Computer Gaming Laboratory, with the investigator guiding participants through the experiment. Volunteers included 22 students enrolled in various courses, and 4 staff members; all of whom had no prior background in physics. Participants were asked to complete the first part of the questionnaire (comprising demographics and the pre-test), and then to play the game in the classical physics mode to familiarise themselves with the game interface. After this, the investigator gave a verbal overview of relativity to provide context, and users were asked to play the game a second time under the relativistic physics model (or practise mode if they so chose). In general, participants were not directed but allowed to discover the game's physics rules and explore its behaviour by themselves. Discussion was also allowed; approximately half of the participants engaged with one another to analyse the game physics behaviour, or ask questions of the investigator. Finally, participants completed the post-test and evaluation sections of the questionnaire, and were thanked for their time. Each experiment session lasted about an hour, with about 30 minutes between pre- and post-tests; this necessarily limited the amount of time for participants to reflect and form new ideas for answering the test, but kept the time commitment for participants manageable.

Experiments were also conducted with classes of HSC physics students from three local high schools, with the cooperation and oversight of the teachers. These followed broadly the same procedure, except that the teachers were able to direct and incorporate the activity into a lesson, and often used it to foster discussion with their class on relativity topics. As students were involved in different stages of their curriculum, for some classes this was a first introduction to relativity, and for others it formed a revision activity. 


\section{Results and analysis}

The focus group studies involved a total of 67 participants (see Table 1 earlier). These were divided into two cohorts, of 39 subjects new to relativity (26 university volunteers and 13 HSC students), and 28 subjects with prior classroom exposure (28 HSC students).

\section{Test section responses}

The 8 questions of the test section of the survey were summarised in Table 2 of the previous section. Figures 5 and 6 graph the correct pre- and post-treatment response rates of the participants to each question, and the averaged total score.

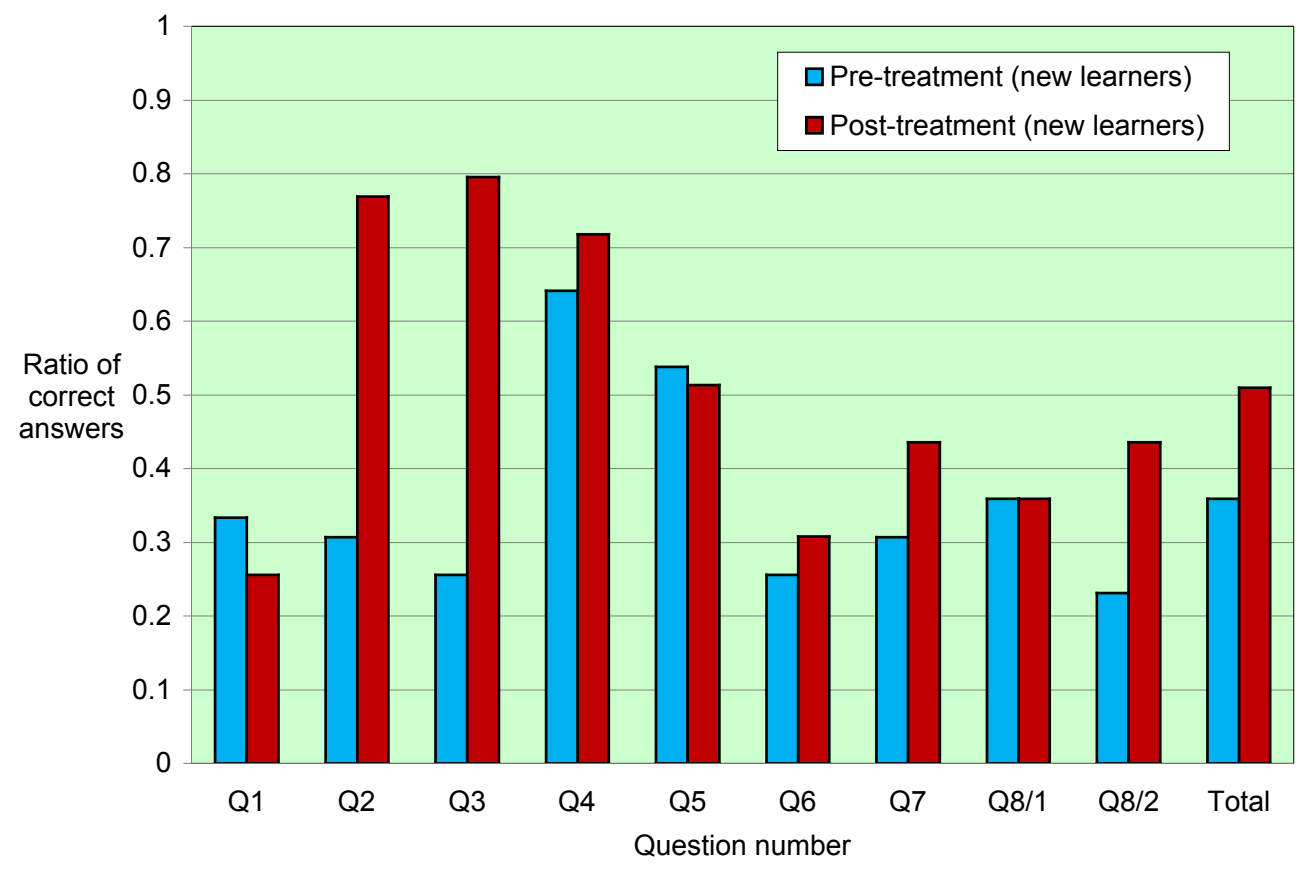

Figure 5: Graph of test scores for participants new to relativity ( $\mathrm{n}=39$ university participants and HSC students).

Data was analysed using SPSS, and Microsoft Excel with programmed formulae. We are interested in knowing whether exposure to the game improves each subject's score in the test to a statistically significant degree. To answer this, the total scores were analysed using a Wilcoxon signed-rank test for non-normally distributed paired data. The probability or $p$-values obtained from these analyses are presented in Table 4; statistically significant results at the 5\% level (i.e. <0.05) are marked with an asterisk. The results show a strongly significant result for the new learners, although both cohorts showed improved test scores in the post-test. 


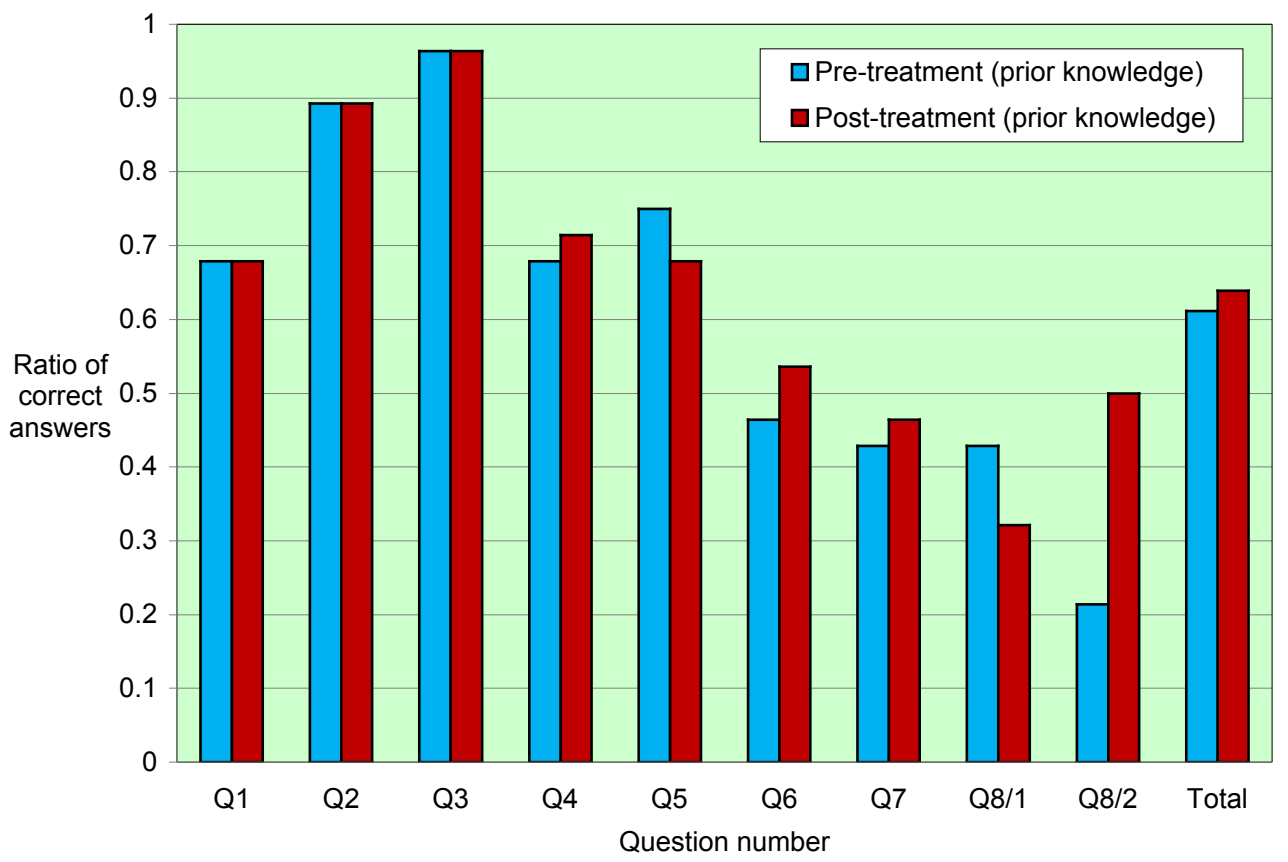

Figure 6: Graph of test scores for participants who had previously studied relativity in class ( $\mathrm{n}=28$ HSC students)

Table 4: The test scores, and $p$-values for participants' improvement across the test

\begin{tabular}{|l|l|c|c|}
\hline \multicolumn{2}{|c|}{} & $\begin{array}{c}\text { New learners } \\
\text { group }(\mathrm{n}=39)\end{array}$ & $\begin{array}{c}\text { Prior knowledge } \\
\text { group }(\mathrm{n}=28)\end{array}$ \\
\hline \multirow{2}{*}{ Pre-test } & Mean & 0.359 & 0.611 \\
\cline { 2 - 4 } & Std. dev. & 0.208 & 0.185 \\
\hline \multirow{2}{*}{ Post-test } & Mean & 0.510 & 0.639 \\
\cline { 2 - 4 } & Std. dev. & 0.185 & 0.178 \\
\hline$p$-value & $0.0049^{*}$ & 0.365 \\
\hline
\end{tabular}

In addition, we can examine each question individually to identify where the greatest shifts occurred. The pair-wise change in correct responses to each question was analysed using a two-sample sign test (since the change between correct/incorrect is bimodal). The resulting chance probabilities, $Q$, are given in Table 5; again, the significant results (less than 0.05) are marked with an asterisk.

This analysis shows highly significant increased understanding among the new learners cohort for the questions concerning length contraction and mass dilation (Q2 and Q3). While these respondents also improved on Q4 concerning time dilation, the improvement was not great enough to be significant; it is interesting to note that the new learner cohort showed a high prior understanding of this concept in the pre-test with correct rates over $60 \%$. By contrast, the prior knowledge cohort showed no significant improvement across these questions, demonstrating these concepts were already well understood in the pre-test. 
Table 5: The chance probabilities, $Q$, for the change in responses to each test question

\begin{tabular}{|c|c|c|}
\hline Question & $\begin{array}{c}\text { New learners } \\
\text { group }(\mathrm{n}=39)\end{array}$ & $\begin{array}{c}\text { Prior knowledge } \\
\text { group }(\mathrm{n}=28)\end{array}$ \\
\hline Q1 & 0.186 & - \\
\hline Q2 & $0.000072^{*}$ & 0.240 \\
\hline Q3 & $0.000015^{*}$ & - \\
\hline Q4 & 0.273 & 0.500 \\
\hline Q5 & 0.386 & 0.240 \\
\hline Q6 & 0.362 & 0.500 \\
\hline Q7 & 0.134 & 0.309 \\
\hline Q8/1 & 0.386 & 0.225 \\
\hline Q8/2 & $0.021^{*}$ & $0.013^{*}$ \\
\hline
\end{tabular}

Most of the remaining questions did not result in obviously useful outcomes. These were questions concerned with peripheral topics less central to the game experience (such as Q1, stating the postulates of relativity), or that required deeper reflection and problem solving. The major exception to this was Q8/2, concerning redshift/blueshift, wherein both cohorts showed significantly improved comprehension of colour shift for approaching and receding objects.

\section{Evaluation section responses}

The ten statements given to the participants for the evaluation of the game are listed in Table 3, allocated along the VGT dimensions. Responses were recorded in the range +2 (Strongly agree) to -2 (Strongly disagree). Table 6 shows the mean and standard deviation of the responses collected from the participant cohorts, and the proportion of 'Agree' and 'Strongly agree' responses (inverse statements are starred). The overall responses are represented in the graph in Figure 7. The boxes show the area one standard deviation either side of the mean response score. The lines show the maximum and minimum scores received for each statement.

Table 6: Summary of participant evaluations of the game

\begin{tabular}{|c|c|c|c|c|c|c|c|c|c|c|c|}
\hline \multirow{4}{*}{$\begin{array}{l}\text { New } \\
\text { learners } \\
\text { group }\end{array}$} & & V1 & $\mathrm{V} 2$ & G1 & $\mathrm{G}^{*}$ & $\mathrm{G}^{*}$ & G4 & $\mathrm{T} 1$ & $\mathrm{~T} 2$ & T3 & $\mathrm{T} 4$ \\
\hline & Mean & 1.18 & 1.27 & 1.15 & -1.15 & -1.08 & 1.13 & 0.89 & 1.13 & 0.87 & 0.37 \\
\hline & Std. dev. & 0.60 & 0.65 & 0.63 & 0.90 & 0.70 & 0.80 & 0.80 & 0.80 & 0.83 & 0.90 \\
\hline & $\begin{array}{l}\% \text { Agree/ } \\
\text { Strongly agree }\end{array}$ & $90 \%$ & $85 \%$ & $87 \%$ & $82 \%$ * & $85 \%{ }^{*}$ & $79 \%$ & $72 \%$ & $79 \%$ & $74 \%$ & $46 \%$ \\
\hline \multirow{3}{*}{$\begin{array}{l}\text { Prior } \\
\text { knowledge } \\
\text { group }\end{array}$} & Mean & 1.25 & 1.29 & 1.04 & -1.21 & -0.71 & 1.08 & 1.21 & 1.25 & 1.04 & 0.67 \\
\hline & Std. dev. & 0.53 & 0.62 & 0.46 & 0.66 & 0.81 & 0.50 & 0.51 & 0.61 & 0.75 & 0.82 \\
\hline & $\begin{array}{l}\text { \% Agree/ } \\
\text { Strongly agree }\end{array}$ & $82 \%$ & $79 \%$ & $79 \%$ & $75 \% *$ & $64 \%{ }^{*}$ & $79 \%$ & $82 \%$ & $79 \%$ & $71 \%$ & $54 \%$ \\
\hline
\end{tabular}

Participants overall rated the game favourably, regarding it as fun (item V1, overall $87 \%$ agree or strongly agree), and that it made the topic more entertaining and motivating to learn (V2, 82\%). Both cohorts agreed equally that playing the game represented an effective way to learn about relativity $(\mathrm{G} 4,79 \%)$.

The new learners cohort felt more strongly that they had learnt from the activity $(85 \%$ versus $64 \%$ disagreement with the negatively-worded statement of item G3). However, respondents experienced in the topic felt more that the game clearly demonstrated the differences between classical and relativistic physics (T1, 82\% versus $72 \%$ agreement). 


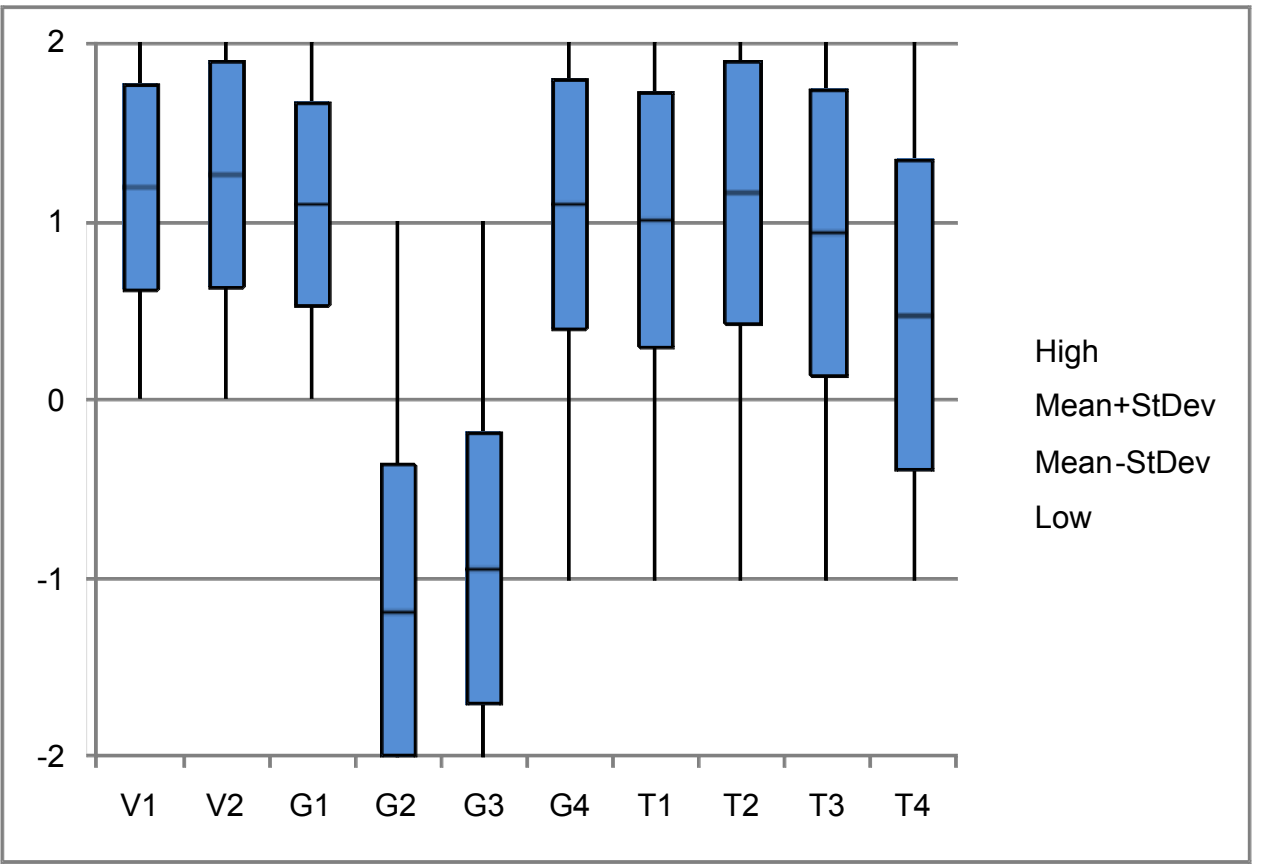

Figure 7: Graph of combined participant responses to the 10 evaluation statements

There was strong correlation between the evaluations, user comments and learning result, regarding the specific effectiveness of the portrayal of the principal relativistic effects. The length contraction and mass dilation effects (items T2 and T3) were both deemed effective, but time dilation (T4) was particularly singled out as needing to be more pronounced.

\section{User comments}

Open-ended questions solicited user comments on the best features of the game, areas that could be improved, and general thoughts.

Regarding best features, responses frequently referred to the graphical portrayal of physics, especially seeing the "changing shape" for length contraction, and colourshifting effect. The simplistic game graphics were also cited as an area that could be improved; but some responses contended that simplicity of the game was an advantage. The interactivity and challenge/fun factors of the game were also mentioned as positive aspects.

Besides the graphics, other suggestions for general improvement mentioned the addition of sound effects, more varied gameplay, and more/clearer instruction and explanation. Individual usability issues were also raised, but were not generally uniform. Specific comments regarding the physics clearly singled out the time dilation as needing to be less subtle. In addition, respondents suggested the inclusion of mechanisms to experience other related physics effects (switching the frame of reference to be relative to the spaceship, and the relativity of simultaneity). 
In general comments, many respondents expressed appreciation of the game activity (e.g. "great fun"). Other studies have reported how interactive technologies can help learners build more intuitive explanations (Squire et al, 2004) or make physics topics less abstract (McGrath et al, 2008), and this was also reflected in comments we received, such as "I think it could be of great practical use in school to learn about what I find an off the planet and dry subject" and "putting theory into practice". However, some criticisms were also offered up, with some respondents (predominantly from the new learners cohort) indicating they only found it confusing. Specific feedback suggested that more information and guidance would help support communication of the relativistic effects.

The teachers involved in the studies gave very positive comments about using the game with their classes. These are examined more closely in the following discussion of the research questions.

\section{Discussion}

In this section we address our research questions, and reflect on the implications.

$R Q$ I: Can computer game software embodying relativistic principles provide an effective scaffold for learning of the Theory of Relativity?

The results of the test administered in the experiment indicate that an improvement did take place in the ability of the participants to correctly answer exam-style questions on relativity. Thus, we affirm that the game did convey knowledge and assist players in learning of relativity.

The most significant improvements appeared in the concepts of length contraction (Q2) and mass dilation (Q3), which the game obviously embodies very well. This improvement was only true for the new learners group of participants, where the correct answer ratio jumped from around $25 \%$ (consistent with random chance) to over $70 \%$. By comparison, the prior knowledge cohort showed initially high results on these questions, and effectively no overall change after treatment. However, both cohorts returned statistically significant learning results for the final question on Doppler shift of colour $(\mathrm{Q} 8 / 2)$. Both cohorts also tended to improve their scores across most other questions $(\mathrm{Q} 4, \mathrm{Q6}, \mathrm{Q} 7)$ and returned an increased total score for the test.

Additionally, the user evaluations indicated that the participants felt that the game was effective for learning, and clearly portrayed relativistic effects in helpful ways. In comments, participants expressed appreciation for the game context as a novel way to present physics, and that they felt it made the material less abstract, a result also shared by McGrath et al (2008).

RQ II: How does learning with the game compare to or supplement the knowledge gained from formal classroom tuition?

Investigation of this research question in future would ideally involve a comparative study between the two modes of learning - classroom (control), and game (treatment). However, the results of the current investigation do provide some useful insights and outcomes. 
The physics students involved in this study were studying relativity according to the HSC curriculum, which outlines proficiency in the principal features of relativity including length contraction, time dilation, reference frames, and applying the Lorentz equations (Board of Studies, 2010). The five factual questions (Q1-5) of the test map most closely to this curriculum, while Q6 and Q7 are more advanced questions requiring manipulation of mathematics.

The prior knowledge group show generally high correct answer rates, particularly across questions Q1-5, indicating most concepts were already well understood. In the pre-test, the new learners group show answer rates across most questions consistent with random chance (having no prior familiarity). However, it is notable that the new learners score initially high results $(>0.6)$ on concepts of time dilation (Q4) and constancy of the speed of light (Q5). This indicates that most participants may have encountered these topics before (e.g. hearing about the 'twin paradox').

In the post-test, the answer profile of the new learners becomes markedly closely aligned to that of the prior knowledge group (within 13\% of the total overall score). Notably, the game was clearly a powerful introduction for new learners on the concepts of length contraction $(\mathrm{Q} 2)$ and mass dilation $(\mathrm{Q} 3)$, where they increase their understanding to be close to the prior knowledge group; but it did nothing for them on the postulates of relativity (Q1). However, both cohorts return a significant learning result for the Doppler shift effect of colour (Q8/2), which is a concept that is not covered in the HSC. This indicates the learners were able to retain and interpret this concept represented in the game for answering the test question.

It is also notable that the correct answer rates of both cohorts move in identical directions between the pre and post-tests, across Q4, Q6 and Q7 (increase) and Q5 (decrease). The reason for the decrease in Q5 might indicate confusion with the game's usage of the Mr Tompkins-style 'slow light'.

Our learning outcomes are especially interesting in light of the report by Dimitriadi, Halkia and Skordoulis (2010), who conducted a study in learning relativity using a range of educational media. They mention length contraction and time dilation as two of the more difficult concepts for students to grasp; but also that it was much more difficult for the learners to deal with length contraction, than time dilation. The latter may tie into our result of higher initial comprehension; while regarding the former, it appears that our game is much more successful in communicating length contraction than the methods and media those authors employed. However, this study did not probe understanding in great enough detail to ascertain that subjects actually achieved rigorously correct interpretations. Other studies have shown that students often adopt only partially-correct conceptual frameworks that allow them to incorrectly retain old ideas, attributing difficulties to distortions of perception for example (Scherr, Shaffer \& Vokos, 2001; Dimitriadi, Halkia \& Skordoulis, 2005). Thus, while our result is promising, further research is required to determine what conceptual change has taken place for teaching practice to build upon and reinforce.

The teachers that were involved in the study gave positive reflections of using the game and the experiment activity with their classes. They generally used the game as a vehicle for initiating classroom discussion and illustrating concepts. Detailed feedback from one of the teachers is quoted below. This teacher felt the game was a useful resource, although she indicated the experience would be improved with more time 
for students to explore and reflect. She described how she would utilise it in her class as a learning resource for students to explore over a longer period.

I thought the game was great. It was very beneficial that I... could explain what was happening and what they should be looking out for. The year 12's enjoyed it as they had an understanding of what it was all about. However, they needed more time to play the game and get a hold of all they could see.

I would certainly use it in a classroom environment [...]. I would give it to them as a resource but introduce it in a double lesson and then let them take it home to play. I think it is a wonderful resource that is... a bit different and worth exploring and the game is a great way to do this.

RQ III: What design and implementation factors can be identified that would make such educational relativity games appeal to, motivate and engage a diverse audience without compromising learning?

With this question, we examine what features of our current game are successful or not successful, for application to future work.

The computer game is a novel and useful means to portray relativity, which is difficult to otherwise observe or visualise. Our study participants responded generally positively, reporting they found it made the topic more relatable and entertaining. Teachers also regarded it as a useful resource for exploration. Although implemented as a single player game, it was observed among some participants to inspire friendly competition as they sought to beat one another's scores, and to foster discussion between learners in the classroom. This may reflect an emergent preference for sharing learning experiences, as was also witnessed by Squire et al (2004). More features could be added to allow the game to be used in collaborative learning (Zuiker et al, 2008; Stewart, 2009), such as linked scoreboards and multi-player environments.

Relativity lends itself to an action-game portrayal, dealing as it does with scenarios involving high speed motion. However, accessibility is an important consideration, as not everyone may naturally possess the hand-eye coordination required for fast-paced games (as an alternative, puzzle or turn-based game designs usually eliminate the issue of reflexes). Observation and results showed that of those participants who were HSC students, age, gender and prior gaming experience had no significant impact on their experiences with the game in the experiment. However, in the university volunteer cohort, a few subjects in particular had difficulty grasping how to control the game. The introduction of the 'practise' mode to our design was one result of early feedback, to improve usability for less confident gamers by removing the penalty of dying, as well as to facilitate freer experimentation (Carr, 2010).

This game was developed on constructivist principles, which outline that learning occurs by confronting misconceptions in one's conceptual frameworks and reifying by the construction of new frameworks. Traditionally, paradoxes are used to elicit learners' incorrect conceptions and motivate the formation of new ones, but the learning is most powerful when learners discover and reflect for themselves (Scherr, Shaffer \& Vokos, 2002). Our game provides an environment in which players can interact with and qualitatively observe the physics through experimentation, hopefully discovering new dynamics and behaviours. The game environment is open-ended and unstructured, however, and relies on self-motivation of the learner to explore. As 
Zuiker et al (2008) writes, “[games] can only ever frustrate and facilitate various trajectories of [inquiry]"; teachers are still important to guide learning and motivate willingness in students to re-examine their embedded epistemic stances.

Some important outcomes highlighted in this study arise from the user feedback concerning information content. Comments suggested "the physics concepts need to be more reinforced at the front end of the game" and "the game is only really effective as a learning tool when the player has someone nearby to explain what is happening". One particularly astute student stated that "the physics principles from this game are [only] learnt via observation skills...", and along with other comments, suggested that an in depth information section, on screen text, or audio commentary would help support communication of the relativistic effects. These would be important factors to consider for developing the game to act in a more stand-alone capacity; however, it is a worthwhile point to remember that 'gamers rarely read manuals' (Schiller, 2008; Stewart, 2009). Indeed, the current version of our game included a brief 'help screen' text synopsis about the physics, but our participants either were not aware of it or chose to ignore it.

Instead, the gamer's preferred method of learning is by trial and error, learning by doing. Our game provided a semi-open environment for players to experiment in, but this could be taken further. For example, Stewart (2009) outlines the use of pop-up "light bulb" notes that point out interesting features, which are not revealed upfront but emerge through dedicated play. These serve as both a motivator for players to find, and to present relevant information 'just in time' for players to use. Schiller (2008) examined the puzzle game Portal, and found it embodies very carefully designed learning methodologies and content. It uses scaffolded instruction, and layers lessons to make skill acquisition and demonstration central to the game. Portal takes the common training mission or tutorial level one step further; in fact, for most of its duration, learning is the game. Following this example, our game could be improved with structured "missions" to guide the attention of players to the particular features we want them to learn, and test their understanding.

Observation also revealed an issue with the combination of conceptual and representative visual effects (Carr, 2010). When the colour-changing of objects was explained during an experiment session as a representation of Doppler shift, one participant asked if the expanded object outline (intended for mass dilation, but which appears "glowing") was also a relativistic effect. This highlights that the combination of graphics effects for different purposes needs to be carefully considered to avoid confusion.

\section{Conclusion}

Central to the design of Relativistic Asteroids is incorporating the physics principles that are our learning material into the rules of the game itself. A realistic portrayal is deemphasised, in favour of a stylised representation to focus on the dynamics. Respondents found placing the physics into a game context was a motivating and unique way to engage with the concepts, and it was effective at improving their comprehension of selected physics effects. The goal-oriented context motivates them to unravel the behaviour of the system to improve their ability, and implicitly frames their trajectory of inquiry and provides measurement of aptitude. 
The current version of Relativistic Asteroids is effective at introducing some concepts of special relativity to learners, aligned with the current HSC physics curriculum. Our future work would aim to improve this software to address the points we have discussed from the findings of this study. We also plan to develop these game ideas and mechanics into a fully 3D game, incorporating the relativistic visualisation techniques described by for example Savage, Searle \& McCalman (2007). We would conduct further studies to analyse and compare these representations and the effectiveness of game technologies for enhancing learning of difficult topics like relativistic physics.

\section{Acknowledgments}

This work is funded by a Charles Sturt University Postgraduate Research Studentship (CSUPRS) scholarship and the Centre for Research in Complex Systems (CRiCS).

\section{References}

Amory, A. (2007). Game object model version II: A theoretical framework for educational game development. Educational Technology Research and Development, 55(1), 51-77. http: / / dx.doi.org/10.1007/ s11423-006-9001-x

Andriole, S. J. \& Roberts, E. (2008). Technology curriculum for the 21st century. Communications of the ACM, 51(7), 27-32. http:/ / dx.doi.org/10.1145/1364782.1364792

Boas, M. L. (1961). Apparent shape of large objects at relativistic speeds. American Journal of Physics, 29(5), 283-286. http:/ / dx.doi.org/10.1119/1.1937751

Board of Studies NSW (2010). HSC Syllabuses - Physics. [viewed 23 July 2010]. http: / / www.boardofstudies.nsw.edu.au/syllabus_hsc/physics.html

Carr, D. (2010). Visual computer game features for teaching relativity. In E. Banissi, M. Sarfraz \& M. L. Huang (Eds), Proceedings of the Seventh International Conference on Computer Graphics, Imaging and Visualization (CGIV10), 35-40. http: / / dx.doi.org/10.1109/ CGIV.2010.13

Carr, D., Bossomaier, T. \& Lodge, K. (2007). Designing a computer game to teach Einstein's theory of relativity. In Banissi, E., Sarfraz, M. \& Dejdumrong, N. (Eds), Proceedings of the Fourth International Conference on Computer Graphics, Imaging and Visualisation (CGIV07), 109114. http:/ / dx.doi.org/10.1109/CGIV.2007.35

Davis, F. D. (1989). Perceived usefulness, perceived ease of use, and user acceptance of information technology. MIS Quarterly, 13(3), 319-340. http: / / misq.org/perceivedusefulness-perceived-ease-of-use-and-user-acceptance-of-informationtechnology.html?SID=moiicjlb2bfeu2rfs980980600

Dimitriadi, K., Halkia, K. \& Skordoulis, C. (2005). Basic concepts of special theory of relativity in secondary education: Do students understand them? E-proceedings of the 2005 ESERA conference "Contributions of Research to Enhancing Students Interest in Learning Science". http: / / asel.primedu.uoa.gr/PAPERS/BasicConceptsOfSpecialTheory.pdf

Dimitriadi, K., Halkia, K. \& Skordoulis, C. (2010). An attempt to teach the Theory of Special Relativity to students of upper secondary education. In Çakmakci, G. \& Tasar, M. F. (Eds), Proceedings of ESERA 2009 "Contemporary science education research: Learning and assessment", 183-187, Ankara, Turkey: Pegem Akademi. http:/ / www.esera2009.org/books/Book_4.pdf

Dondlinger, M. J. (2007). Educational video game design: A review of the literature. Journal of Applied Educational Technology, 4(1), 21-31. [verified 15 Sep 2011] http: / / www.eduquery.com/jaet/JAET4-1_Dondlinger.pdf 
Egenfeldt-Nielsen, S. (2007). Third generation educational use of computer games. Journal of Educational Multimedia and Hypermedia, 16(3), 263-281. http:/ / www.editlib.org/p/24375

Einstein, A. (1924). Relativity: The special and general theory. Authorised translation Lawson, R. W. (Ed). Methuen \& Co Ltd.

de Freitas, S. (2006). Learning in immersive worlds: A review of game-based learning. Joint Information Systems Committee (JISC), Bristol. [viewed 17 Sep 2010]. http:/ / www.jisc. ac.uk/whatwedo/ programmes/ elearninginnovation/ outcomes/gamingreport.aspx

Gamow, G. (1940). Mr Tompkins in Wonderland. Macmillan. http:/ / books.google.com/books/ about/Mr_Tompkins_in_paperback.html?id=TMSnBgPMExMC

Gee, J. P. (2003). What video games have to teach us about learning and literacy. Palgrave Macmillan.

Gibbs, P., Carr, J. \& Koks, D. (2008). What is relativistic mass? [viewed 18 May 2009]. http:/ / math.ucr.edu/ home/baez/physics / Relativity/SR/mass.html

Gorriz, C. \& Medina, C. (2000). Engaging girls with computers through software games. Communications of the ACM, 43(1), 42-49. http: / / dx.doi.org/10.1145/323830.323843

Gros, B. (2007). Digital games in education: The design of games-based learning environments. Journal of Research on Technology in Education, 40(1), 23-38. http: / / www.iste.org/Store / Product.aspx?ID=1325; http: / / uoc.academia.edu/Bego\%C3\%B1aGros/Papers / 216763/ Digital_Games_In_Education_The_Design_of_Games-Based_Learning_Environments

Hsiung, P.-K. \& Dunn, R. H. P. (1989). Visualizing relativistic effects in spacetime. Proceedings of the 1989 ACM/IEEE conference on Supercomputing, pp 597-606, ACM Press. http: / / dx.doi.org/ 10.1145/76263.76331

Ip, B., Jacobs, G. \& Watkins, A. (2008). Gaming frequency and academic performance. Australasian Journal of Educational Technology, 24(4), 355-373. http:/ / www.ascilite.org.au/ajet/ajet24/ip.html

Kaminski, J. A., Sloutsky, V. M. \& Heckler, A. F. (2008). The advantage of abstract examples in learning math. Science, 320(5875), 454-455. http:/ / dx.doi.org/10.1126/science.1154659

Kiili, K. (2007). Foundation for problem-based gaming. British Journal of Educational Technology, 38(3), 394-404. http: / / dx.doi.org/10.1111/j.1467-8535.2007.00704.x

Mayo, M. J. (2007). Games for science and engineering education. Communications of the ACM, 50(7), 30-35. http:/ / dx.doi.org/10.1145/1272516.1272536

Mayo, M. J. (2009). Video games: A route to large-scale STEM education? Science, 323(5910), 7982. http: / / dx.doi.org/10.1126/ science.1166900

McGrath, D., Savage, C., Williamson, M., Wegener, M. \& McIntyre, T. (2008). Teaching special relativity using virtual reality. In A. Hugman \& K. Placing (Eds), Proceedings of the UniServe Science Symposium on Visualisation and Concept Development, 67-73. http:// sydney.edu.au/science/ uniserve_science/pubs/procs/2008/067.pdf

McGrath, D., Wegener, M., McIntyre, T. J., Savage, C. \& Williamson, M. (2010). Student experiences of virtual reality - a case study in learning special relativity. American Journal of Physics, 78(8), 862-868. http:/ / dx.doi.org/10.1119/1.3431565

Prensky, M. (2001). Digital game-based learning. McGraw-Hill.

Price, C. B. (2006). A crisis in physics education: Games to the rescue! ITALICS (Innovation in Teaching And Learning in Information and Computer Sciences), 5(3). [viewed 8 Sep 2010]. http:// www.ics.heacademy.ac.uk/italics/vol5iss3.htm 
Price, C. B. (2007). Computer games as vehicles to learn physics: Mechanics, oscillations and waves. Proceedings of the 38th Conference of the International Simulation and Gaming Association.

Price, C. B. (2008). The usability of a commercial game physics engine to develop physics educational materials: An investigation. Simulation E Gaming, 39, 319-337. http: / / dx.doi.org/10.1177/1046878108319579

Rashid, R. (2008). Image crisis: Inspiring a new generation of computer scientists. Communications of the ACM, 51(7), 33-34. http: / / dx.doi.org/10.1145/1364782.1364793

Ritter, L. A. \& Sue, V. M. (2007). Special issue: Using online surveys in evaluation. New Directions for Evaluation, 115. http: / / dx.doi.org/10.1002/ ev.230

Savage, C. M. \& Searle, A. C. (1999). Visualising special relativity. The Physicist, 36(141). http:/ / www.anu.edu.au/Physics/Searle/ paper2.pdf

Savage, C. M., Searle, A. C., \& McCalman, L. (2007). Real time relativity: Exploratory learning of special relativity. American Journal of Physics, 75(9), 791-798. http: / / dx.doi.org/10.1119/1.2744048

Savage, C. M., McGrath, D., McIntyre, T. J., Wegener, M. \& Williamson, M. (2010). Teaching physics using virtual reality. AIP Conference Proceedings: Proceedings of the International Conference on Physics Education (ICPE-2009), 1263, 126-129. http: / / dx.doi.org/10.1063/1.3479848

Scherr, R. E., Shaffer, P. S. \& Vokos, S. (2001). Student understanding of time in special relativity: Simultaneity and reference frames. American Journal of Physics, 69(S1), S24-S35. http: / / dx.doi.org/10.1119/1.1371254

Scherr, R. E., Shaffer, P. S. \& Vokos, S. (2002). The challenge of changing deeply held student beliefs about the relativity of simultaneity. American Journal of Physics, 70(12), 1238-1248. http: / / dx.doi.org/10.1119/1.1509420

Schiller, N. (2008). A portal to student learning: what instruction librarians can learn from video game design. Reference Services Review, 36(4), 351-365. http: / / dx.doi.org/10.1108/00907320810920333

Scott, G. D. \& van Driel, H. J. (1970). Geometrical appearances at relativistic speeds. American Journal of Physics, 38(8), 971-977. http: / / dx.doi.org/10.1119/1.1976550

Shayer, M., Ginsburg, D. \& Coe, R. (2007). Thirty years on - a large anti-Flynn effect? The Piagetian test Volume E Heaviness norms 1975-2003. British Journal of Educational Psychology, 77(1), 25-41. http:/ / dx.doi.org/10.1348/000709906X96987

Spector, P. E. (1985). Measurement of human service staff satisfaction: Development of the Job Satisfaction Survey. American Journal of Community Psychology, 13, 693-713. http: / / dx.doi.org/10.1007/BF00929796

Squire, K., Barnett, M., Grant, J. M. \& Higginbotham, T. (2004). Electromagnetism supercharged!: Learning physics with digital simulation games. Proceedings of the 6th International Conference on Learning Sciences, International Society of the Learning Sciences. http: / / www.educationarcade.org/ files/articles/Supercharged/SuperchargedResearch.pdf

Stewart, P. M. (2009). Does the 3D serious game Physics Geeks facilitate learning in conceptual physics students? Teachers College Educational Technology Conference 2009 Conference Proceedings, 32-34. http: / / events.tc.columbia.edu/tcetc2009/TCETC2009_Proceedings.pdf 
Strachota, E., Schmidt, S. W. \& Conceição, S. C. O. (2006). The Development and Validation of a Survey Instrument for the Evaluation of Instructional Aids. Proceedings of the 2006 Midwest Research-to-Practice Conference in Adult, Continuing, Extension, and Community Education, University of Missouri-St. Louis, pp 205-210.

Terrell, J. (1959). Invisibility of the Lorentz contraction. Physical Review, 116, 1041-1045. http: / / dx.doi.org/10.1103/ PhysRev.116.1041

Weiskopf, D., Kraus, U. \& Ruder, H. (1999). Searchlight and Doppler effects in the visualization of special relativity: A corrected derivation of the transformation of radiance. ACM Transactions on Graphics, 18, 278-292. http:/ / dx.doi.org/10.1145/336414.336459

Weiskopf, D., Borchers, M., Ertl, T., Falk, M., Fechtig, O., Frank, R., Grave, F., King, A., Kraus, U., Müller, T., Nollert, H.-P., Mendez, I. R., Ruder, H., Schafhitzel, T., Schär, S., Zahn, C. \& Zatloukal, M. (2005). Visualization in the Einstein year 2005: A case study on explanatory and illustrative visualization of relativity and astrophysics. IEEE Visualization 2005 Proceedings. http: / / dx.doi.org/10.1109/VISUAL.2005.1532845

Wikipedia (2010). Asteroids (video game). [viewed 14 Sep 2010]. http: / / en.wikipedia.org/wiki/ Asteroids_(video_game)

Zuiker, S. J., Anderson, K. T., Lee, J. L. H. \& Chee, Y. S. (2008). Designing for the epistemological entailments of physics through game-centered dialogical activity cycles. In Kirschner, P., Prins, F., Jonker, V. \& Kanselaar, G. (Eds), Proceedings of the 8th International Conference of the Learning Sciences: International Perspectives in the Learning Sciences: Cre8ing a Learning World, 2, 516-523. http: / / lsl.nie.edu.sg/publications / documents / game-centered-dialogical-activitycycles

\section{Appendix A: The Special Theory of Relativity (mathematical)}

The following is a heavily condensed outline of the mathematical equations underpinning Special Relativity. To recapitulate, the two postulates of special relativity are:

1. The laws of physics are the same to all inertial observers.

1. The speed of light is the same to all inertial observers.

In order to complete his theory, Einstein had to throw out accepted notions of space and time as being invariant across all frames of reference, replacing them with the assertion that the speed of light is invariant. Because it is invariant, the numerical value of the speed of light, $c$, can be considered a conversion factor between different frames of reference.

The description of an 'event' with respect to space and time is given by the three space coordinates, $x, y$ and $z$ and time value $t$. (Einstein combined these four values together to give a joint coordinate system called spacetime.) We consider a first coordinate system denoted $K$, and a second coordinate system $K$ which is axis-aligned with $K$ and travelling with a velocity $v$ along the $x$-direction of $K$, and ask: given the magnitudes $(x, y, z, t)$ of an event with respect to $K$, what are the corresponding values $\left(x^{\prime}, y^{\prime}, z^{\prime}, t^{\prime}\right)$ of the same event in $K^{\prime}$ ? In order to preserve the second postulate, the relations that solve this problem are: 


$$
\begin{gathered}
x^{\prime}=(x-v t) \gamma \\
y^{\prime}=y \\
z^{\prime}=z \\
t^{\prime}=\left(t-\frac{\beta x}{c}\right) \gamma
\end{gathered}
$$

where

$$
\begin{gathered}
\beta=\frac{v}{c} \\
\gamma=\frac{1}{\sqrt{1-\beta^{2}}}
\end{gathered}
$$

This system of equations is known as the "Lorentz transformation". From the Lorentz transformation equations we can describe the behaviour of measurements of lengths of space and time as follows. Say we have a object with a known rest length, $x_{0}$, and want to know its length as measured when travelling at relative speed $v$. Defining the length to be found as $x(v)$, then the relation between them is given by

$$
x(v)=x_{0} \sqrt{1-\beta^{2}}
$$

As $v$ approaches the speed of light $c$, so $x(v)$ will tend to be smaller than $x_{0}$; a contraction of space with increasing speed. Likewise if we have a measure of time $t_{0}$ in the rest frame, and want to know what corresponding amount of time $t(v)$ passes in the moving frame,

$$
t(v)=\frac{t_{0}}{\sqrt{1-\beta^{2}}}
$$

With increasing speed $v, t(v)$ will be a somewhat longer time than $t_{0}$, therefore time is dilated. Finally, for an object of mass $m_{0}$, the kinetic energy is no longer given by $m v^{2} / 2$ but by

$$
\frac{m c^{2}}{\sqrt{1-\beta^{2}}}
$$

which results in a somewhat larger value for the kinetic energy as velocity increases. If the energy content (given by $E=m c^{2}$ ) is taken to include kinetic energy, it is sometimes said (see Gibbs, Carr \& Koks, 2008) that mass increases with increasing speed, which is described by the following equation:

$$
m(v)=\frac{E}{c^{2}}=\frac{m_{0}}{\sqrt{1-\beta^{2}}}
$$

These equations are the basis for our statements about length contraction, time dilation, and mass dilation. An object that is in motion relative to an observer will 
experience these effects; likewise, no matter how fast an observer travels in relation to a light source, that observer will always measure the speed of light to be the same value.

\section{Appendix B: Test section questions}

1. Which of the following pairs of statements correctly describe the Special Theory of Relativity?

a. The speed of light $c$ is constant in all inertial frames of reference. The laws of physics are the same in all inertial frames of reference.

a. The speed of light $c$ is constant in all inertial frames of reference. The laws of physics are different in different inertial frames of reference.

a. The speed of light $c$ is different in different inertial frames of reference. The laws of physics are the same in all inertial frames of reference.

a. The speed of light $c$ is different in different inertial frames of reference. The laws of physics are different in different inertial frames of reference.

2. A stationary observer is watching a relatively moving rocket travelling at high speed. The observer makes a measurement of the rocket's length. As the rocket approaches the speed of light, what happens to the length measured by the observer?

a. The length of the rocket increases.

a. The length of the rocket decreases.

a. The length of the rocket stays the same.

a. More information is needed about the rest length and speed of the rocket.

3. A particle accelerator is a device used to accelerate electrically-charged particles to high speeds. A particle has a mass of $m_{0}$ at rest. A scientist takes measurements of the mass of the particle as it is accelerated to relativistic speed. As the particle approaches the speed of light, what will the observer measure for its mass?

a. The mass of the particle will increase.

a. The mass of the particle will decrease.

a. The mass of the particle will stay the same.

a. More information is needed about the method used to measure the mass.

4. A stationary observer is watching a relatively moving rocket travelling at high speed. The rocket carries a clock which ticks at the rate of 1 second per second in the rocket's frame of reference. As the rocket approaches the speed of light, at what rate will the clock appear to tick to the observer?

a. The clock will tick slower.

a. The clock will tick faster.

a. The clock will tick at the same rate.

a. More information is needed about the clock.

5. A rocket is travelling at 50\% of the speed of light relative to a stationary observer. The rocket switches on a headlight which sends out a light signal travelling away from 
the rocket at $100 \%$ of speed of light. What speed will the observer measure the light signal travelling at?
a. $50 \%$
b. $100 \%$
c. $150 \%$
d. $200 \%$

6. If an airline pilot flies 80 hours per month (in her rest frame) at $200 \mathrm{~m} / \mathrm{s}$ for 25 years, what will be the difference in ages between her age and that of her twin brother (who works in the airport control tower) when she retires?
a. The pilot will be 19 minutes younger.
b. The pilot will be 19 microsecond younger.
c. The pilot will be 19 microseconds older.
d. The pilot will be 19 minutes older.

7. A train passes through a station at relativistic speed. Pat, the station master at the railway station, observes that the front of the train passes one end of the platform (call this event $A$ ) at the same moment as the rear of the train passes the other end of the platform (event $B$ ). Alice, a passenger on the train, also observes these events. What sequence of events would Alice describe?
a. Event $A$ happens before $B$.
b. Event $B$ happens before $A$.
c. Both happen at the same moment.
d. More information is required about the lengths of the train and platform.

8. As part of a science experiment, two spacecraft (Alpha and Beta) are travelling towards one another at $60 \%$ the speed of light. Spacecraft Alpha turns on a headlight pointed at Spacecraft Beta. Spacecraft Beta carries scientific instruments to perform measurements on the light coming from Alpha. What effects on the light will be seen by Beta? (Select as many answers as apply):

- The speed of the approaching light beam will be faster than $c$.

- The speed of the approaching light beam will be slower than $c$.

- The light coming from Alpha will be brighter.

- The light coming from Alpha will be darker.

- The light coming from Alpha will be redshifted.

- The light coming from Alpha will be blueshifted.

\author{
Authors: David Carr and Professor Terry Bossomaier \\ Centre for Research in Complex Systems (CRiCS) \\ Charles Sturt University, Panorama Ave, Bathurst, NSW 2795, Australia \\ Email: dcarr@csu.edu.au, tbossomaier@csu.edu.au \\ Web: http: / / charybdis.mit.csu.edu.au/crics/, http: / / csusap.csu.edu.au/ dcarr
}

Please cite as: Carr, D. \& Bossomaier, T. (2011). Relativity in a rock field: A study of physics learning with a computer game. Australasian Journal of Educational Technology, 27(6), 1042-1067. http: / / www.ascilite.org.au / ajet/ ajet27 / carr.html 